\title{
The Determinants of the Volatility in Cryptocurrency Markets: The Bitcoin Case
}

Murat Akkaya*

İstanbul Arel University

\begin{abstract}
This article analyzes the volatility in the cryptocurrency markets. Cryptocurrencies have come to the fore especially in recent years. They have no global border and are easy to use. The earliest example of a cryptocurrency was Bitcoin, first introduced in an article by Satoshi Nakamoto (2008). This study examines symmetries and asymmetries in the Bitcoin price and the expected leverage effect. The GARCH $(1,1)$ model is statistically significant at the $1 \%$. EUR/USD buying rate, GOLD price, USD10 Year Bond Yield, US Dollar Index and VIX variables are significant. The interaction between international financial variables and Bitcoin volatility emerge in the period of study. The EGARCH model indicates that the leverage effect is not valid in the cryptocurrency markets.
\end{abstract}

Keywords: Cryptocurrency, Bitcoin, Volatility, Garch, Volatility Spillover, EGarch.

Jel Classification: E40, G19, C50, C49, C51

\section{Kripto Para Piyasalarına Oynaklık Faktörleri: Bitcoin Vakası}

$\ddot{O} \mathbf{z}$

Bu makale kripto para piyasalarındaki oynaklığı analiz etmektedir. Kripto para birimleri özellikle son yıllarda ön plana çıktı. Küresel sınırları yoktur ve kullanımı kolaydır. Kripto para biriminin ilk ortaya çıkış1, Nakamoto'nun (2008) bir makalesiyle Bitcoin'dur. Kripto para ve madeni para piyasaları getiri sağlarken aynı zamanda oynaklık sağlamaktadır. Bu çalışma, Bitcoin fiyatındaki simetri ve asimetrileri ve beklenen kaldıraç etkisini incelemektedir. GARCH $(1,1)$ modeli \%1'de istatistiksel olarak anlamlıdır. EUR/USD alış kuru, ALTIN fiyatı, USD10 Y1l tahvil getirisi, ABD Doları Endeksi ve VIX değişkenleri anlamlıdır. Uluslararası finansal değişkenler ile Bitcoin oynaklığı arasındaki etkileşim, inceleme döneminde geçerlidir. EGARCH modeli, kaldıraç etkisinin kripto para piyasalarında geçerli olmadığını göstermektedir.

Anahtar Kelimeler: Kripto Para, Bitcoin, Oynaklık, Garch, Oynaklık Yayılımı, EGarch. Jel Sinıflandirmasi: E40, G19, C50, C49, C51

\footnotetext{
* Assoc. Professor, International Trade and Finance, İstanbul Arel University. Email: muratakkaya@ arel.edu.tr. Phone: +90 850 8508735/1219. ORCID: 0000-0002-7071-8662
} 
$\mathrm{T}$ his study aims to extend the existing literature of volatility and asymmetric effects in cryptocurrency markets by investigating daily return flows from the financial markets of developed countries and international commodity markets. This study differs from other studies in that it adds international financial market variables and volatility indices to the model. In addition, this study examines the asymmetric movements in the Bitcoin price and the expected leverage effect. Bad news increases volatility in financial markets more than good news, and accordingly, the response to bad news in financial markets and the response to good news are not similar or symmetrical.

Cryptocurrencies are not under the jurisdiction of any governmental institution. They are decentralized and use cryptography. Although cryptocurrencies have come to the fore especially in recent years, they have a historical background. Nick Szabo introduced digital currencies called "egold" in 1996 and Wei Dai formulated "b-money" in 1998 (Marr, 2017). An intense interest has taken place recently in cryptocurrencies developed through Blockchain technology, which was designed as a payment system and ushers in a new period for the global payments, digital assets and decentralized management legal systems (Wright \& De Filippi, 2015). Blockchain technology is a distributed database which uses cryptology. A data-driven chain structure lies in the logic of each blockchain transaction. This chain starts with the first data entry and can continue indefinitely.

The first emergence of cryptocurrency was Bitcoin and was initially discussed in an article entitled "Bitcoin; Peer to Peer Electronic Cash System" written by Nakamoto (2008). Bitcoin miners create Bitcoins. Blockchain and mining constitute the infrastructure of the Bitcoin system. Mining is an integral process for generating and verifying cryptocurrency transactions. It ensures the stable and secure spread of the currency from the sender to the recipient. Banks that produce and monitor physical and electronic currency require large infrastructures to carry out their transactions. Cryptocurrencies overcome this need by implementing a mining system that monitors and approves the money-generating transactions of people on the network called "miners" or "nodes". Mining is a protocol defined and implemented in software and a fundamental function in the management of the cryptocurrency network. Mining validates transactions, avoids double spending, collects transactions and creates a money supply.

The popularity of Blockchain technology has increased significantly with the cryptocurrency Bitcoin. Bitcoin is a decentralized, encrypted network digital asset. The biggest feature that makes Bitcoin different is that it changes hands directly between the buyer and the seller in the digital space without the need for an authority. Encryption (cryptography) principles are used to control the creation and exchange of Bitcoin, which includes an advanced technology called Blockchain. The most important distinguishing feature of Bitcoin is that it is controlled by a software algorithm and not by a person, group, company, central authority or government, compared to standard fiat money units such as the Dollar or the Euro. The supply of Bitcoin, which is in the strongest position among cryptocurrencies, is limited to 21 million units. Provided that the system works correctly, by 2140 the maximum amount of Bitcoin in circulation will reach 21 million units and the growth rate will converge to zero. Bitcoin has begun to be accepted as a means of payment on international platforms. The use of Bitcoin is becoming widespread in both internet and shopping transactions: the number of businesses accepting Bitcoin is increasing day by day. Apart from the traditional economic definition, Bitcoin is an investment and savings tool. Investors realize their financial and real investments by using the new money form as an investment channel.

The first Bitcoin was published by "bitcointalk" members in May 2010 and the value of Bitcoin against the US dollar at first issue was 0.004. The Bitcoin open-source code was first used in 2011

The Determinants of the Volatility in CryptocurRency Markets: The Bitcoin CASE 
to create sub coins. The maximum number of Bitcoin was limited to 21 million. After Bitcoin, various cryptocurrencies such as Ethereum, Ripple, Bitcoin Cash and Lite emerged. Some countries recognized and accepted crypto currencies. Japan, as the first example, accepted the crypto currency and approved its use as money. Some countries such as China, Egypt, Iceland, Iran, Pakistan, Qatar, and Saudi Arabia banned the use of cryptocurrencies. "www.coinmarketcap.com" which is an important platform for crypto currencies, consists of 4.933 different crypto currencies as of May 03, 2021, and the global crypto market value now exceeds 2.31 Trillion USD. Figure 1 presents the Bitcoin (BTC) prices from the first trading day on the Chicago Board Options Exchange (CBOE) until March 31, 2021. Bitcoin price rose sharply during the Covid-19 period.

Figure 1 BTC prices from 11 December 2017 to 31 March 2021

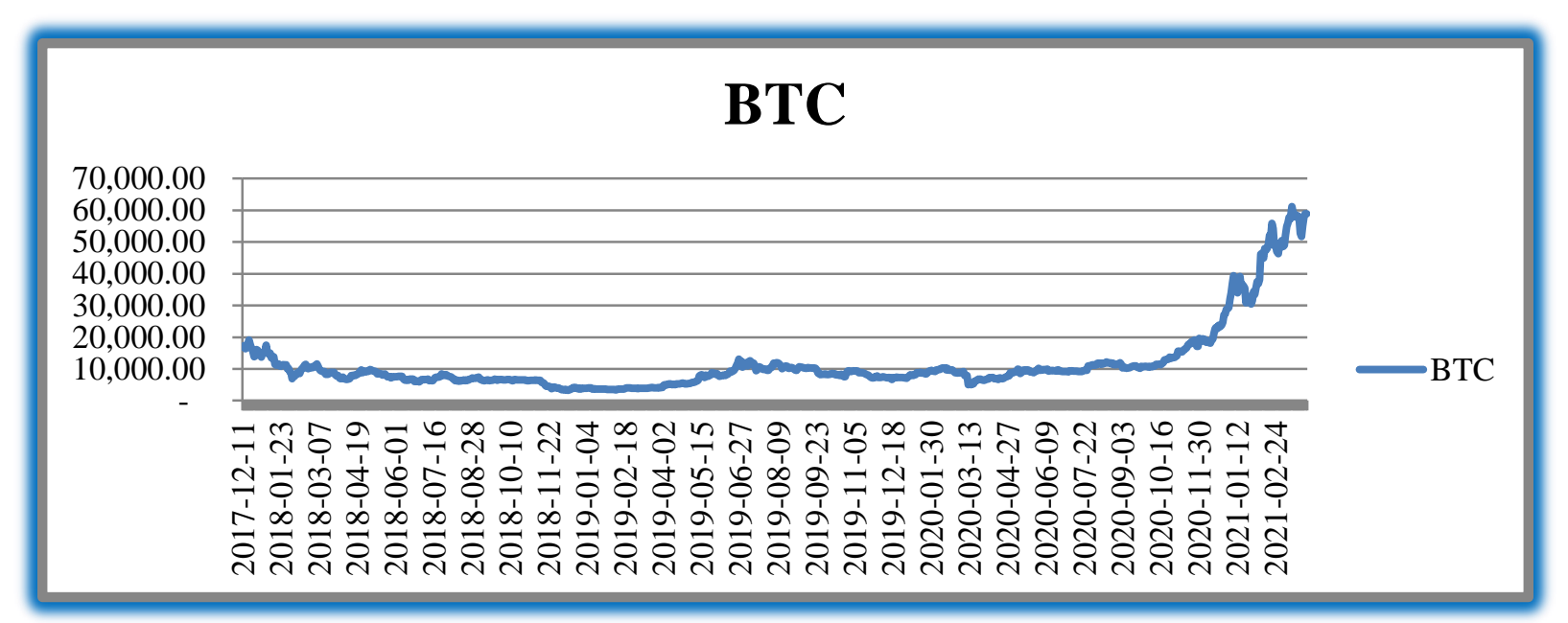

The popularity of cryptocurrencies increases especially in the COVID-19 epidemic. Financial institutions invest in the creation of digital currency technologies, and blockchain-based technology entries are growing. But in reality, their valuations, transaction volumes, and user bases are largely responsive to news about regulatory actions. News pointing to the creation of tailored legal frameworks for cryptocurrencies and initial coin offerings coincides with strong market gain and increase volatility.

\section{Literature Review}

An increasing number of individuals and companies invest in Bitcoin, the world's largest and first fully functional cryptocurrency. The growing popularity also affects studies on Bitcoin. Bitcoin price formation, price determinants and bubble studies come to the fore due to extreme fluctuations in price.

Bitcoin price formation have been studied by Buchholz et al. (2012), Van Wijk (2013), Kristoufek (2013) and Bouoiyour and Selmi (2015). An important determinant of the Bitcoin price is the interaction between Bitcoin supply and demand (Buchholz et al. 2012). The price movements of Bitcoins stem from investor interest, and the relationships are more pronounced in the long run. Bitcoin is not a safe investment tool (Kristoufek, 2015). BTC, Ethereum, Litecoin, Ripple and S\&P 500 indices with 10-day VaR and Expected Shortfall (ES) methods indicate that cryptocurrencies carry a high risk (Stavroyiannis, 2017). Especially, the price of crude oil, the Dollar/Chinese Yuan 
exchange rate and the difficulty of Bitcoin mining have a significant impact on the Bitcoin price level formation (Seys, 2016).

The extreme volatility of cryptocurrencies has also attracted the attention of researchers recently. Bitcoin (BTC) continues to have the highest transaction volume in the cryptocurrency market. BTC shares several similar features to gold and the dollar as a hedging tool. BTC combines investment and savings features in financial markets and portfolio management. BTC has high returns and volatility and low correlation with investment instruments. Therefore, it provides benefits in portfolio diversification (Brière et al. 2015). Financial indicators including the Dow-Jones index, euro-dollar rate and oil price significantly affect the price of Bitcoin in the long run (Van Wijk, 2013). The FAVAR model indicates that the main factor for the Bitcoin price formation is its popularity (Goczek \& Skliarov, 201)).

Generalized Autoregressive Conditionally Heteroscedastic (GARCH) models present many findings about Bitcoin volatility. The volatility of BTC varies over time and is valid in the long term. BTC is ideal for risk-taker investors (Dyhrberg, 2016). An internal process mainly leads to the price fluctuations. These unexpected and unknown shocks have a significant effect on the price of Bitcoin. In addition, demand side factors are positively correlated with the price of Bitcoin (Vockathaler, 2015). Positive shocks increase conditional volatility more than negative shocks. (Bouri et al. 2017). The Dow Jones Industrial Average (DJIA), Bitcoin demand and gold price affect Bitcoin price fluctuations in the short and long term. Bitcoin supply affects the price fluctuation in the short term and not in the long term (Sukamulja \& Sikora, 2018). BTC exhibits different return, volatility and correlation characteristics compared to other assets, including gold and dollars (Baur et al. 2018). BTC and gold have fundamentally different characteristics as assets. BTC has a significant relationship with stock markets (Klein et al. 2018). Transaction volume and Google search density affect the volatility of Bitcoin returns (Figá-Talamanca \& Patacca, 2019). The Lasso approach also proves a relation with search intensity and gold returns (Panagiotidis et al. 2018) Speculative demand also statistically affects BTC price formation (Ciaian et al. 2018). Entropy is an important factor in explaining Bitcoin price and return. The entropy coefficient is positive and significant. This indicates that Bitcoin's price dynamics may stem from market uncertainty (Pele \& Mazurencu-MarinescuPele, 2019). The statistically significant spillover effects occur in the cryptocurrency market of the United States, as well as in other leading economies (Liu \& Serletis, 2019). The standard MIDAS model proves a jump-driven time-varying transition probability between the two regimes (Ma et al. 2020). The more sophisticated volatility models including leverage and time-varying skewness may improve volatility predictions at different forecast horizons compared to more standard alternatives (Catania et al. 2021). The path is from dominant cryptocurrencies with higher market capitalization and information transmission to sentiments. The COVID-19 pandemic has increased the connectedness of cryptocurrencies (Akyildirim et al. 2021). Polat et al. (2021) examine Bitcoin's return, volatility and transaction volume and observe that the excessive uncertainty led by the outbreak and an increase in fear sentiment negatively affect the BTC returns. Aysan et al. (2021) focus on the sources of Bitcoin research, types of documents, important platforms and highly cited studies, and present the current state and future path of Bitcoin literature from distinct perspectives.

Bitcoin volatility studies using the Exponential GARCH (EGARCH) model contain conflicting results compared to other models. The EGARCH model is the most powerful model in volatility studies. Changes in US stock markets affect BTC volatility (Koy et al. 2021). The decentralization mechanism of Bitcoin causes high volatility (Şahin \& Özkan, 2018). Fear sentiment

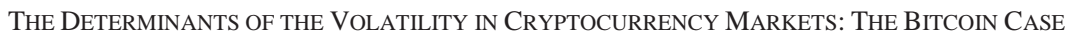


regarding the Coronavirus also leads to negative Bitcoin returns and high trading volume (Chen et al. 2020).

\section{Data}

This study aims to analyze volatility in cryptocurrency markets using daily Bitcoin price as a fundamental proxy in the period from 11 December 2017 to 31 March 2021. The starting day of the study is the Bitcoin's first trading day on the Chicago Board of Exchange (CBOE). Thus, BTC has reached many investors by trading in derivatives markets. Table 1 defines variables and abbreviations. This study models independent variables that are most commonly used in international financial markets as leading indicators by investors. The significant changes in these variables may create stress and volatility in financial markets which in turn may affect investor risk appetite and confidence.

Table $1 \quad$ Variables

\begin{tabular}{ll}
\hline Abbreviation & Variable \\
\hline BTC & Bitcoin price in US Dollar \\
EUR/USD & Euro/US Dollar buying rate \\
NASDAQ & Nasdaq Stock Market Exchange Index - USA \\
NIKKEI & Tokyo Stock Market Exchange - Japan \\
OIL & Brent oil price \\
GOLD & Gold ounce price \\
USDINX & US Dollar Index \\
USD10 & US 10-year bond yield \\
VIX & Volatility Index by Chicago Board Options Exchange (CBOE) \\
\hline
\end{tabular}

\section{Analysis and Results}

Table 2 shows the correlations of BTC with variables. The highest correlation is between BTC and NIKKEI Tokyo Stock Exchange (0.8370). The second is the Nasdaq Index (0.7212). The lowest correlation is with the US Dollar Index (-0.4797). As expected, it is inversely correlated with the US Dollar Index and the US 10-Year Bond Rate.

Table 2 Correlation Matrix

$\begin{array}{lrrrrrrrr} & \underline{\text { EUR/USD }} & \underline{\text { GOLD }} & \underline{\text { NASDAQ }} & \underline{\text { NIKKEI }} & \underline{\text { OIL }} & \underline{\text { USD10 }} & \underline{\text { USDINX }} & \underline{\text { VIX }} \\ \text { BTC } & 0.4189 & 0.47949 & 0.7212 & 0.8370 & -0,0504 & -0,3241 & -0,4797 & 0.0658\end{array}$

Dyhrberg (2016) applies the GARCH model using exchange rates, gold price, The Financial Times Stock Exchange 100 Index (FTSE) and Federal Funds rate to determine the BTC's volatility. This paper follows Dyhrberg's approach to detect the volatility in the cryptocurrency markets.

The GARCH is a frequently preferred model for volatility in financial markets. In particular, the methods for modeling financial series such as returns may violate the homoscedasticity assumption. In such a case, heteroscedasticity should also be considered. In the most general terms, the ARCH model can eliminate this problem. One of the serious problems of the ARCH model proposed by Engle (1982), however, is that the lag for too many error terms is statistically significant, 
that is, a high "p" parameter estimation is required. Bollerslev (1986) proposes the Generalized Autoregressive Conditional Heteroskedasticity (GARCH) model to solve the problem of the ARCH model. In the GARCH model, conditional variance is defined as an ARMA (p, q) process that includes the terms autoregressive and moving average. In addition, the GARCH model has a more flexible lag structure.

The variables in the GARCH models should be stationary. It would be appropriate to use the Augmented Dickey Fuller (ADF) test developed by Dickey \& Fuller (1981) for the test of stationarity. Table 3 presents the results from a Augmented Dickey Fuller unit root analysis.

Table 3 ADF Test results

\begin{tabular}{lrrrc}
\hline Variables & \multicolumn{1}{l}{ t-Statistic } & Prob.* & t-Statistic & 1. Diff. Prob.* \\
\hline BTC & 3.455015 & 1.0000 & -28.6445 & 0.0000 \\
EUR/USD & -1.606593 & 0.4788 & -28.2486 & 0.0000 \\
NASDAQ & 0.267286 & 0.9765 & -36.6109 & 0.0000 \\
NIKKEI & -0.549303 & 0.8787 & -18.8722 & 0.0000 \\
OIL & -1.447398 & 0.5599 & -29.2317 & 0.0000 \\
GOLD & -0.981003 & 0.7616 & -28.5578 & 0.0000 \\
USDINX & -1.664997 & 0.4488 & -27.4098 & 0.0000 \\
USD10 & -0.828318 & 0.8101 & -29.1758 & 0.0000 \\
VIX & -2.634200 & 0.0663 & -3.5847 & 0.0063 \\
\hline
\end{tabular}

The ADF unit root test indicates that the variables are not stationary at the level, but they are stationary in their first differences. For this reason, modeling goes on by taking the differences of variables from the 1 st degree to ensure the stationary assumption.

The first step in estimating the Generalized Autoregressive Conditional Heteroskedasticity model is to determine the presence of ARCH effect in the model. Table 4 presents the results from ARCH estimations.

Table 4 ARCH LM Test results

\begin{tabular}{lcc}
\hline Variables & t-Statistic & Prob.* $^{*}$ \\
\hline BTC & 55676.65 & 0,0000 \\
EUR/USD & 17572.77 & 0,0000 \\
NASDAQ & 61219.97 & 0,0000 \\
NIKKEI & 36123.01 & 0,0000 \\
OIL & 28890.36 & 0,0000 \\
GOLD & 33929.32 & 0,0000 \\
USDINX & 14307.35 & 0,0000 \\
USD10 & 43145.68 & 0,0000 \\
VIX & 3551.44 & 0,0000 \\
\hline
\end{tabular}

The F-statistic value for each variable is statistically significant at the $1 \%$ level. Accordingly, the presence of heteroscedasticity indicates that the model has ARCH effect. Thus, the price series of the BTC is suitable for the use of ARCH models. Figure 2 shows the BTC ARCH effect. 
Figure 2 Bitcoin ARCH effect graphic

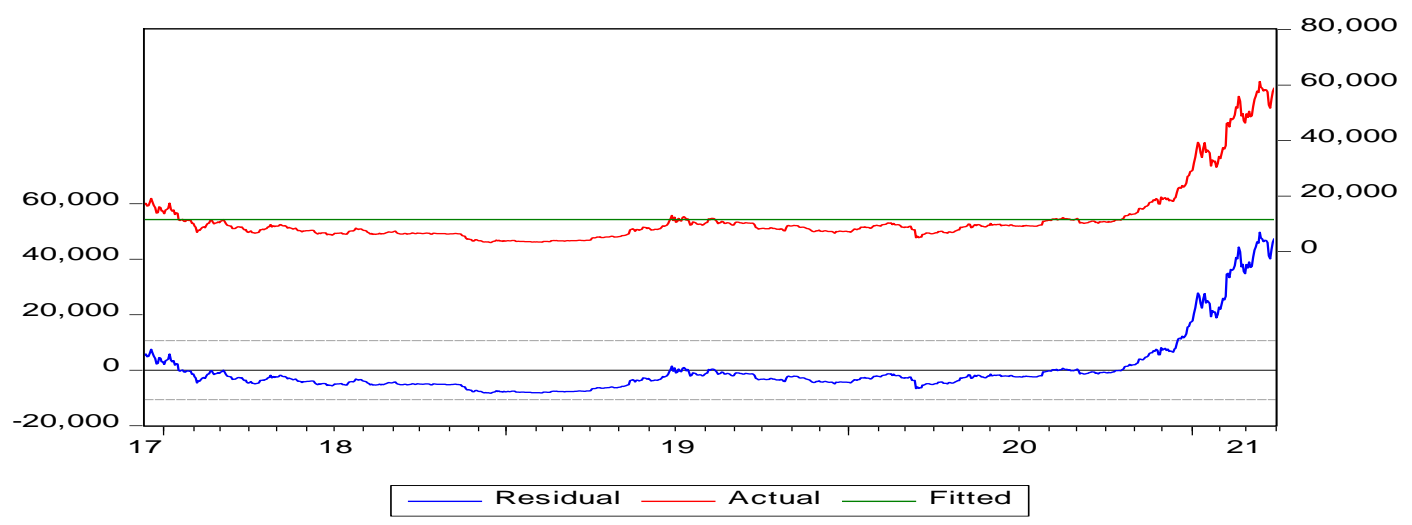

Considering criteria such as non-negative variance coefficients, sum of variance coefficients less than one, homoscedastic residuals and significant coefficients, the most appropriate model is GARCH (1,1). Equations (1) describe the mean and variance equations to determine the volatility of the BTC price series, respectively.

$$
\begin{gathered}
d\left(B T C_{t}\right)=\beta_{0}+\beta_{1} d\left(B T C_{t-1}\right)+\beta_{2} d\left((\text { EUR/USD })_{t}\right)+\beta_{3} d\left(N A S D A Q_{t}\right)+ \\
\beta_{4} d\left(N I K K E I_{t}\right)+\beta_{5} d\left(\text { OIL }_{t}\right)+\beta_{6} d\left(G O L D_{t}\right)+\beta_{7} d\left(\text { USDINX }_{t}\right)+\beta_{8} d\left(U S D 10_{t}\right)+\beta_{9} d\left(\text { VIX }_{t}\right) \\
\epsilon_{t} \sim N\left(0, h_{t}\right)
\end{gathered}
$$

The estimation results of the GARCH $(1,1)$ model are presented in Table 5.

Table 5 GARCH Test results

\begin{tabular}{lrrrr}
\hline \multicolumn{1}{c}{ Variable } & Coefficient & Std. Error & Z-Statistic & \multicolumn{1}{c}{ Prob. } \\
\hline EUR/USD & $-19147,02$ & 2279,93 & $-8,39807$ & $0,0000^{*}$ \\
GOLD & $-10,21$ & 3,641175 & $-2,80322$ & $0,0051^{*}$ \\
NASDAQ & $-0,21$ & 0,393716 & $-0,52226$ & 0,6015 \\
NIKKEI & 0,33 & 0,235033 & 1,406643 & 0,1595 \\
OIL & 60,73 & 41,60222 & 1,459721 & 0,1444 \\
USD10 & $-6419,24$ & 755,3383 & $-8,4985$ & $0,0000^{*}$ \\
USD_INX & $-1013,17$ & 80,5291 & $-12,5814$ & $0,0000^{*}$ \\
VIX & $-71,38$ & 30,20467 & $-2,36312$ & 0,0181 \\
C & 147334,00 & 11139,94 & 13,22574 & 0,0000 \\
\hline \multicolumn{1}{c}{ C } & Variance Equation & & \\
\hline \multicolumn{1}{c}{ RESID $(-1)^{\wedge} 2$} & 16639031 & 1700541 & 9,784549 & $0,0000^{*}$ \\
\multicolumn{1}{r}{ GARCH(-1) } & 0,9213 & 0,17671 & 5,213441 & $0,0000^{*}$ \\
\hline
\end{tabular}

The GARCH $(1,1)$ model is statistically significant at the $1 \%$ level, and the model is valid. EUR/USD buying rate, GOLD price, USD 10-year bond yield, US Dollar Index and VIX variables in the GARCH model created for modeling the volatility of BTC are significant. NASDAQ and NIKKEI Index and oil prices do not have impact on the BTC volatility.

In conventional ARCH / GARCH models, only the magnitude of the shock is important and its sign is ignored. That is, conditional variance is assumed to be symmetrical in response to positive 
and negative shocks. However, negative shocks increase volatility more than positive shocks in financial markets. Nelson (1991) develops the Exponential Generalized Autoregressive Conditional Heteroscedastic (EGARCH) model, that is the dynamic model that captures volatility clustering in return series. EGARCH has been extensively applied to measure the volatility spread in the global stock market. In the EGARCH model, the volatility measures the stickiness and the variance term depends on two parameters, its own lags and the condition of the standard error term. The EGARCH model can be formulized as follows:

$$
\log \left(\sigma_{t}^{2}\right)=\omega+\sum_{k=1}^{q} \beta_{k} g\left(Z_{t-k}\right)+\sum_{k=1}^{p} \alpha_{k} \log \sigma_{t-t}^{2}
$$

The paper follows Kanas' (1998) approach detecting the volatility spillover to cryptocurrency markets. Kanas' insight is to set the conditional values for coefficients and test their statistical significance. Let us assume that the volatility spread from VIX to BTC is examined by considering the EGARCH $(1,1)$ model.

$$
\log \left(h_{B T C, t}\right)=\alpha_{0}+\theta_{1}\left(\frac{\mu_{t-i}}{\sqrt{h_{B T C, t-1}}}\right)+\alpha_{1}\left|\frac{\mu_{t-i}}{\sqrt{h_{B T C-1}}}\right|+\beta_{1} \log \left(h_{B T C-1}\right)+\varphi_{1} \log \left(\mathrm{U}_{\mathrm{VIX}, \mathrm{t}}\right)
$$

In equation (3) $\alpha_{1}$ shows the effect of $\mathrm{ARCH} ; \theta_{1}$, asymmetric $\mathrm{ARCH}$ effect; $\beta_{1}$ represents volatility stickiness and UVIXt represents squares of error terms derived from the EGARCH model estimated for VIX. The volatility spread is determined by looking at the statistical significance of the $\boldsymbol{\varphi}_{1}$ coefficient. If $\boldsymbol{\varphi}_{1}$ coefficient is statistically significant, this would imply that the volatility spreads from the VIX to BTC.

EGARCH $(1,1)$ is an appropriate model to determine the volatility spread among variables (Table 6).

\section{Table 6 EGARCH $(1,1)$ results}

\begin{tabular}{lrrrr}
\hline Variable & $\boldsymbol{\varphi}$ & $\boldsymbol{n}$ & $\boldsymbol{\lambda}$ & $\boldsymbol{\theta}$ \\
\hline BTC & 0,0378 & 0,0773 & 0,4893 & 0,6246 \\
\hline
\end{tabular}

EGARCH results indicate that the asymmetric effect parameter $\left(\lambda\right.$ or $\left.\mu_{t-1} / h_{t-1}\right)$ appears to be positive and statistically not significant at $1 \%$. The asymmetric effect does not take place. In other words, the leverage effect is not valid in the cryptocurrency markets. The empirical results do not prove the volatility spread from stock and commodity markets to cryptocurrency markets.

\section{Conclusion}

Cryptocurrencies are new financial instruments. The main advantages of cryptocurrencies are blockchain technology, having no need for intermediaries in transfers and the offering of alternatives to traditional payment methods with the innovations it creates in its infrastructure. Bitcoin (BTC) is the first cryptocurrency and is still the most common currency in use. BTC was first announced in November 2008 by Satoshi Nakamoto. In addition, nowadays, Ethereum, Ripple Dogecoin, Litecoin are other major cryptocurrencies. Financial technology companies and some countries continue to develop their own cryptocurrencies. This situation implies that cryptocurrencies might attract even more attention soon. The fact that crypto coins do not have any central authority brings some risks in terms of the management of monetary policy. The widespread use of them in the economy may lead to a decrease in the efficiency of central banks in monetary policy. 
This study investigates the volatility and volatility spread among markets on the basis of Dyhrberg's methodology. The analysis focuses on Euro/US Dollar rate, stock prices and commodity prices. The GARCH $(1,1)$ model is statistically significant at the $1 \%$ level. EUR/USD buying rate, Gold ounce price, USD 10-Year bond yield, US Dollar Index and VIX variables for modeling the volatility of BTC are significant. BTC has a volatile structure affected by external financial conditions. BTC price reached the highest value of $\$ 63588.20$ on April $9^{\text {th }}, 2021$. On July 5, BTC price is 34520 . BTC lost $45.7 \%$ of its value between April 9 and July 5. This big drop shows that Bitcoin is a speculative investment asset. The volatility should be considered for short-term investment. EGARCH results do not prove the volatility spread. The leverage effect is not valid in the cryptocurrency markets. The findings are obviously important for trading decisions and investor portfolio formation.

This study sheds light on volatility and volatility spread in cryptocurrency markets. Cryptocurrencies have increased in popularity especially during the COVID-19 pandemic. It will be useful to conduct a separate study for the epidemic period. In addition, volatility can be modelled with FAVAR, artificial intelligence and machine learning models. 


\section{References}

Akyildirim, E., Aysan, A. F., Cepni, O., \& Darendeli, S. P. C. (2021). "Do investor sentiments drive cryptocurrency prices?” Economics Letters, 206, 109980.

Aysan, A. F., Demirtaş, H. B., \& Saraç, M. (2021). “The Ascent of Bitcoin: Bibliometric Analysis of Bitcoin Research" Journal of Risk and Financial Management, 14 (9), 427.

Baur, D. G., Dimpfl, T., \& Kuck, K. (2018). "Bitcoin, gold and the US dollar-A replication and extension," Finance research letters, 25, 103-110.

Bollerslev, T. (1986). "Generalized autoregressive conditional heteroskedasticity." Journal of econometrics, 31(3), 307-327.

Bouoiyour, J. and R. Selmi. (2015). "What Does BitCoin Look Like?" MPRA Paper No. 58091. Germany: University Library of Munich.

Bouri, E., Molnar, P., Azzi, G., Roubaud, D., Hagfors, L. I. (2017). “On The Hedge And Safe Haven Properties Of Bitcoin: Is It Really More Than A Diversifier?," Finance Research Letters, 20, 192-198.

Briere, M., Oosterlinck, K., \& Szafarz, A. (2015). "Virtual currency, tangible return: Portfolio diversification with bitcoin," Journal of Asset Management, 16(6), 365-373.

Buchholz, M., J. Delaney, J. Warren, and J. Parker. 2012. "Bits and Bets, Information, Price Volatility, and Demand for BitCoin, Economics 312." www.bitcointrad ing.com/pdf/bitsandbets.pdf.

Ciaian, P., Kancs, D. A., \& Rajcaniova, M. (2018). "The price of Bitcoin: GARCH evidence from high frequency data," arXiv preprint arXiv:1812.09452.

Chen, C., Liu, L., \& Zhao, N. (2020). "Fear sentiment, uncertainty, and bitcoin price dynamics: The case of COVID-19,” Emerging Markets Finance and Trade, 56(10), 2298-2309.

Dickey, D. A., \& Fuller, W. A. (1981). "Likelihood ratio statistics for autoregressive time series with a unit root," Econometrica: journal of the Econometric Society, 1057-1072..

Dyhrberg, A. H. (2016). "Bitcoin, gold and the dollar-A GARCH volatility analysis," Finance Research Letters, 16, 85-92.

Engle, R. F. (1982). "Autoregressive conditional heteroscedasticity with estimates of the variance of United Kingdom inflation,” Econometrica: Journal of the Econometric Society, 987-1007.

Figá-Talamanca, G., Patacca, M. (2019). "Does market attention affect Bitcoin returns and volatility?" Decisions in Economics and Finance, 42(1), 135-155. https://doi.org/10.1007/s10203-019-0258-7.

Goczek, Ł., \& Skliarov, I. (2019). "What drives the Bitcoin price? A factor augmented error correction mechanism investigation," Applied Economics, 51(59), 6393-6410.

Kanas, A. (1998). "Volatility spillovers across equity markets: European evidence," Applied financial economics, 8(3), 245-256.

Klein, T., Thu, H. P., Walther, T. (2018). "Bitcoin is Not The New Gold-A Comparison Of Volatility, Correlation, And Portfolio Performance," International Review of Financial Analysis, 59, 105-116. 
Kristoufek, L. 2013. "Bitcoin Meets Google Trends and Wikipedia: Quantifying the Relationship between Phenomena of the Internet Era," Scientific Reports,3 (3415): 1-7. doi:10.1038/srep03415.

Kristoufek, L. (2015). "What Are the Main Drivers of the Bitcoin Price? Evidence from Wavelet Coherence Analysis," PLoS ONE, 10(4): e0123923. doi:10.1371/journal.pone.0123923.

Koy, A. Yaman, M. \& Mete, S. (2021). "Kripto paraların volatilite modelinde ABD borsa endekslerinin yeri: bitcoin üzerine bir uygulama," Finansal Araştırmalar ve Çalışmalar Dergisi, 13(24), 159-170.

Nakamoto, S. (2008). Bitcoin: A peer-to-peer electronic cash system.

Nelson D. (1991). "Conditional Heteroskedasticity in Asset Returns: A New Approach," Econometrica, 59(2), 347 - 370.

Marr, B. (2017). "A short history of bitcoin and crypto currency everyone should read," Dostupno na https://www. forbes. com/sites/bernardmarr/2017/12/06/a-short-history-ofbitcoin-andcrypto-currency-everyone-should-read.

Panagiotidis, T., Stengos, T., \& Vravosinos, O. (2018). "On the determinants of bitcoin returns: A LASSO approach,” Finance Research Letters, 27, 235-240.

Pele, D. T., Mazurencu-Marinescu-Pele, M. (2019). "Using High-Frequency Entropy to Forecast Bitcoin's Daily Value at Risk," Entropy, 21(2). https://doi.org/10.3390/e21020102

Polat, A. Y., Aysan, A. F., Tekin, H., \& Tunali, A. S. (2021). "Bitcoin-specific fear sentiment matters in the COVID-19 outbreak," Studies in Economics and Finance.

Seys, J.(2016). “The Evolution of Bitcoin Price Drivers: Moving Towards Stability?," University of Ghent, Faculty of Economics and Business Administration.

Stavroyiannis, S. (2017). "Value-at-Risk and Expected Shortfall for the major digital currencies," arXiv preprint arXiv:1708.09343.

Sukamulja, S. ve Sikora, C.O. (2018). "The New Era Of Financial Innovation: The Determinants Of Bitcoin's Price," Journal of Indonesian Economy and Business, Volume 33, Number 1, 46 64.

Şahin, E. E. \& Özkan, O. (2018). “Asimetrik Volatilitenin Tahmini : Kripto Para Bitcoin Estimation Of Asymmetric Volatility: Crypto Money Application," Bilecik Şeyh Edebali Üniversitesi Sosyal Bilimler Enstitüsü Dergisi, 3(2), 240-247.

Vockathaler, B. (2015). “The Bitcoin Boom: An In Depth Analysis Of The Price Of Bitcoins,” Major Research Paper University Of Ottawa, 1-75.

Van Wijk, D. (2013). "What can be expected from the BitCoin," Erasmus Universiteit Rotterdam, 18. 